\title{
La reorganización de los cuidados familiares en un contexto de migración internacional
}

\author{
Raquel MARTíNEZ BUJÁN \\ Universidade da Coruña \\ rmbujan@udc.es
}

Recibido: 7-4-10

Aceptado: 20-6-10

\section{RESUMEN}

El envejecimiento de la población, los cambios en los deseos socioprofesionales de las mujeres y la pérdida de redes sociales que apoyen los cuidados familiares han desafiado la labor de la protección social y han evidenciado nuevas fórmulas de atención personal en los hogares. La aprobación de un marco estatal de regulación de la dependencia y la proliferación de transferencias económicas han sido las respuestas institucionales para la provisión de cuidados de larga duración. La contratación de una empleada de hogar como cuidadora ha sido la alternativa seguida por las familias, en algunos casos, animadas por el auge de estos subsidios monetarios. Ello ha supuesto un cambio en el régimen de cuidados español, donde la reorganización de los cuidados no pasa por una división sexual y generacional más equilibrada en las tareas asistenciales, sino en la mercantilización de estos trabajos. La aceleración de llegadas de población inmigrante, feminizada y en situación irregular, ha propiciado que este sector de cuidados dentro del servicio doméstico, se convierta en un nicho laboral para las personas extranjeras. El artículo explora las conexiones existentes entre la naturaleza de la protección social y la mercantilización de la asistencia, comparando las estrategias de provisión de cuidados de personas mayores en cada una de las comunidades autónomas según la implicación del estado, el modelo migratorio y la incorporación laboral femenina.

Palabras clave: cuidado familiar, migración femenina, mercantilización, servicio doméstico, protección social, regímenes de cuidados.

\section{The Re-Organization of the Family Care in an International Migration Context}

\begin{abstract}
This paper presents the link between the characteristics of the social protection system and the commodification of the assistance. In order to show this, the care providing strategies for the elderly are analysed in the Autonomous Regions in Spain according to the implication of the state social policy, the migratory model and the incorporation of female native population into the labour market. The aging of population, the changes in the socio-labour expectations of native women and the lost of social networks supporting family care have challenged the role of the social protection system and have shown new ways of personal attention within the households. The governmental replies for the provision of long term care have been based on the passing of the regulation of dependence within the framework of the Spanish state policy and the spread of cash transfers. The hiring of a female domestic worker as a care giver has been the alternative followed by the families, in certain cases encouraged by the raise of these economic benefits. This fact has changed the Spanish care system where the re-organization of care does not imply a more balanced sexual and generational division of assistance tasks, but in the commodification of this work. The sharp increase of feminized and irregular immigrant population has favoured that the care sector in the framework of domestic work becomes a relevant labour niche for foreigners.
\end{abstract}


Key words: family care, female migration, domestic service, social protection, care regimes

\section{REFERENCIA NORMALIZADA}

Martínez Buján, R. (2010). La reorganización de los cuidados familiares en un contexto de migración internacional. Cuadernos de Relaciones Laborales Vol. 29, núm. 1, p. 93-123.

SUMARIO: 1 . Introducción. 2. Buscando la teoría que vincula "inmigración" y "cuidados". 3. Más externalización y similar desequilibrio en el reparto familiar del trabajo de cuidados. 4. El fomento del sector doméstico de cuidados desde las prestaciones económicas. 5. Las variedades del familismo a escala regional. 6. Conclusiones. Referencias bibliográficas

\section{Introducción}

El papel central de la familia como agencia de prestación de asistencia y la mercantilización de la atención personal mediante el servicio doméstico son los principales rasgos de la provisión de cuidados en España. La literatura académica internacional de la última década así lo ha reconocido e incluso ha destacado con análisis comparativos con respecto a otros países europeos como, en Europa del Sur, la parentela se convierte en la institución sobre la que descansa el bienestar (Lyon y Gluksmann, 2008; Bettio et al., 2006). Los datos de la última "Encuesta de Discapacidades, Autonomía Personal y Situaciones de Dependencia" ${ }^{1}$ (INE, 2009) demuestran la importancia de la familia en la prestación de asistencia. El $88 \%$ de los cuidadores principales son un miembro del hogar. Pero si la red familiar no puede por sí misma afrontar los cuidados de las personas dependientes (niños, ancianos, adultos enfermos...) o dispone de los medios económicos suficientes, la estrategia es la contratación de una empleada de hogar. El empleo doméstico es cuidador principal en el 6,4\% de las situaciones y se estima que un $14,5 \%$ de los adultos mayores con dependencia utilizan este recurso. Aunque la cifra puede considerarse escasa en comparación con el número total de hogares que necesitan trabajo de cuidados ${ }^{2}$, esta privatización ha tenido un gran impacto sobre el servicio doméstico, sobre el colectivo de personas que se ocupan en esta actividad, sobre los receptores de los cuidados y sobre la política social destinada a la protección de la dependencia.

Por un lado, ha convertido al servicio doméstico en un "nuevo servicio de hogar", especialmente dirigido a las personas mayores y al que cabría calificar como un "servicio doméstico del envejecimiento". Por otro, ha visibilizado los límites del servicio doméstico tradicional. La intensidad de trabajo que requieren los cuidados modifica las clásicas relaciones entre las familias empleadoras y las empleadas,

\footnotetext{
${ }^{1}$ A lo largo del texto se utilizarán las siglas EDAD para designar a esta fuente de información.

${ }^{2}$ Según los datos de la EDAD el número de personas con dependencia en el año 2008 fue de 2.088.100.
} 
señala la escasez de personas dispuestas a trabajar en esta actividad y demuestra la necesidad de importar mano de obra inmigrante. La repercusión de este empleo sobre la población extranjera femenina ha sido tan elevado que el trabajo de cuidados no profesional se ha convertido en su puerta de entrada al mercado laboral español (Martínez, 2010). El impacto de su demanda ha convertido a esta actividad en la de mayor contribución al desarrollo económico desde el estallido de la crisis en el año 2007.

El envejecimiento de la población y la inserción laboral femenina supone un desafío a la política social, tanto si apoya este sistema de cuidados basado en el familismo y en el servicio doméstico o si refuerza la implantación de cuidados profesionales públicos. Los efectos de la protección social desarrollada por la "Ley de Promoción y Autonomía de las Personas en Situación en Dependencia" (LAAD), más centrada en el ámbito de las prestaciones económicas que en el avance de los servicios sociales, aún no han sido evaluados debido a su reciente aprobación. Este artículo analiza las posibles repercusiones de estas transferencias monetarias en la reorganización del trabajo familiar de cuidados y en su actual tendencia hacia la privatización. Se trata de averiguar si los actuales cambios de la política social han contribuido a enfatizar el rol familiar en las tareas de asistencia o si, por el contrario, se ha dirigido a mitigar la presencia de la parentela en este ámbito.

La argumentación se divide en cuatro apartados. El primero es un bosquejo teórico de la vinculación entre inmigración y cuidados para dilucidar cuál es el lugar en el que las investigaciones internacionales sitúan a la política social española. El segundo describe cómo la ausencia de un reparto equilibrado de la asistencia entre los miembros de la familia ha inducido a una reestructuración de los cuidados basada en la mercantilización en el servicio doméstico. La finalidad es detallar la segmentación del sector privado de cuidados y la posición de la población extranjera en el mismo. El tercero asocia esa externalización a la instauración de una serie de subsidios económicos de atención a la dependencia. Y en el cuarto, se ha incorporado un análisis regional en el que se describe como se combinan los recursos estatales, privados y familiares para clasificar las estrategias autonómicas en la provisión de asistencia. En todas las secciones se hace especial hincapié al cuidado destinado a las personas mayores, por ser el más intensivo y al que se han destinado más recursos estatales.

La metodología utilizada ha sido cuantitativa y se ha apoyado principalmente en la explotación de los microdatos del Instituto Nacional de Estadística de la reciente "Encuesta de Discapacidad, Autonomía Personal y Situaciones de Dependencia" (INE, 2009). También se han incorporado los datos de otras fuentes de información como la "Encuesta de Condiciones de Vida las Personas Mayores" (Abellán et al., 2007) y la "Encuesta de Apoyo Informal" (IMSERSO, 2004a). Para medir la extensión de los servicios sociales y de las transferencias económicas de la LAAD se ha recurrido al "Servicio de Estadísticas de la Subdirección General Adjunta de Valoración, Calidad y Evaluación" (IMSERSO, 2010). 


\section{Buscando la teoría que vincula "inmigración" y "cuidados"}

La combinación entre el trabajo familiar de cuidados y la externalización de la asistencia en el servicio doméstico comienza a ser analizado a finales de los años noventa, cuando aparecen una serie de estudios académicos que clasifican a los países europeos según sus estrategias de cuidados y la naturaleza de los programas de política social destinados a la asistencia personal. Este ámbito de trabajo surge complementario al debate abierto hace tres décadas por la literatura feminista británica en torno a las definiciones del concepto "cuidar"3 y ofrece una ampliación de las dimensiones desde las que se había estudiado a los estados de bienestar.

Ese cuerpo teórico feminista inaugurado en los años ochenta por algunas autoras como Hillary Graham (1983), Janet Finch y Dulcie Groves (1983) comenzó planteando relevantes cuestiones sobre la naturaleza dual del cuidado (al tener el doble componente de amor y trabajo) y sobre como se procedía a la delegación de esta tarea a las familias bajo la justificación de que querer a alguien te permite cuidarlo. Su objetivo consistía en entender la posición de las mujeres en la sociedad a partir del trabajo de cuidados y, por ello, no tuvieron en cuenta las tareas asistenciales efectuadas desde ámbitos externos a la familia. Estas pioneras teóricas, herederas del debate sobre la división sexual del trabajo, estaban interesadas en el reconocimiento de las tareas domésticas como un "trabajo" que no puede ajustarse a los cánones mercantiles porque no se realiza por la obtención de un beneficio económico y además ofrece "afecto" y "cariño", elementos no susceptibles de compra y venta. De ahí su interés en resaltar las dos esferas del cuidado: cuidar es "dar cariño", ofrecer sentimientos de afecto, y también es "trabajo físico" que proporciona bienestar a través de diferentes tareas (limpiando, bañando, dando de comer, poniendo inyecciones...). Sin embargo, estos primeros intentos en definir "cuidado" asimilaron esta actividad como una labor doméstica, que se realiza dentro del hogar y que es llevada a cabo fundamentalmente por los miembros familiares femeninos. Analizar desde este marco analítico la lógica de la mercantilización de los cuidados y el concepto de "cuidar" que operaba en aquellas culturas en las que más se producía esta externalización resultaba muy complicado.

Debido a estas limitaciones el concepto de "cuidar" se renueva en posteriores investigaciones, incorporando la labor realizada por profesionales, voluntarios y personas contratadas en el servicio doméstico. Al aparecer más agentes en la escena de la provisión surge un especial interés por analizar los nexos existentes entre el ámbito público y el privado del cuidado (Ungerson, 1990; Thomas, 1993) derivándose este debate en intentar comprender la naturaleza de la política social en cada país y la forma del reparto de la asistencia y del bienestar entre la familia y el estado.

\footnotetext{
${ }^{3}$ Traducción propia del término "care" con el que se designa en su idioma original este cuerpo teórico.
} 
Comienzan a realizarse tipologías en torno a esta materia siendo la más popular de las clasificaciones la realizada por Gosta Esping-Andersen (1990). Publicada en su libro "Three worlds of welfare capitalism", este autor identifica tres regímenes de bienestar a partir de la mercantilización y del compromiso estatal en la asistencia: el liberal (escasa influencia del estado en la solución de los riesgos sociales), el conservador (la protección social pública está destinada a las personas insertas en el mercado laboral formal) y el socialdemócrata (basado en el universalismo cuenta con una potente red de servicios sociales públicos). Sin embargo, su esquema será cuestionado por considerar que las necesidades sociales se abarcan especialmente desde el estado y el mercado, relegando a la institución familiar un rol de menor trascendencia (Saraceno, 1995).

La escasa relevancia que este autor confiere al análisis de la familia ha sido duramente criticada tanto por académicas feministas que reivindicaban el reconocimiento del verdadero papel que tiene la mujer dentro del estado de bienestar, como por parte de los especialistas en política social, que resaltaron la dificultad de ubicar en esa tipología a los países de Europa del Sur, y entre ellos España, en los que la familia es la agencia fundamental de asistencia. Desde la primera perspectiva, la limitación del análisis de Esping-Andersen estriba en la primacía otorgada al estado y al mercado para la provisión de servicios personales, cuando en realidad esta protección está basada en las diversas relaciones de poder que tienen entre sí las instituciones y la división sexual del trabajo, esferas en las que el género es fundamental ( $\mathrm{O}^{\prime}$ Connor, 1993; Orloff, 1993). El segundo enfoque considera que en los países de Europa del Sur existe una combinación e interrelación específica de los recursos estatales, familiares y privados que engendra un régimen de bienestar propio denominado "modelo mediterráneo" (Moreno, 2001; Ferrera, 1996; Sarasa, 1993). Su característica esencial es que el núcleo familiar es el proveedor principal en momentos de dificultad. Destaca de entre todos el papel desempeñado por la mujer cuyo rol es determinante para el desarrollo del ciclo vital de los miembros de la familia.

A finales de los años noventa, consciente de las críticas formuladas, EspingAndersen incorpora en un texto posterior titulado, "The Social Foundations of Postindustrial Economies" (1998), el concepto "desfamiliarización" para hacer referencia al grado en el que las políticas sociales son capaces de mantener la autonomía de los ciudadanos al margen de la protección económica y social que ofrece el entorno familiar. Pero para esa época el desarrollo científico en este ámbito ya estaba produciendo nuevas investigaciones que clasificaban a los estados de bienestar desde otras variables. Se comienza a defender la utilización de un nuevo marco analítico que incluye las estrategias familiares en la provisión de cuidados, las relaciones existentes entre el estado y la familia y los elementos de subordinación y dependencia subyacentes en ésta.

De ahí que con la llegada del siglo XXI los estudios comparativos de la política social se ajusten al estudio de los recursos de asistencia públicos y privados y se dediquen especialmente al trabajo de cuidados, al ser ésta la principal actividad a la que se dirigen los servicios sociales actuales y cuya cobertura permite avanzar en la autonomía de las mujeres. Estas investigaciones comparativas incorporan las diferen- 
cias culturales, políticas, ideológicas y administrativas que operan en la definición de los servicios sociales de cuidado a escala internacional (Anttonen y Sipilä, 1996). Es así como las clasificaciones de los estados en "regímenes de bienestar" dejan paso a las tipologías de los "regímenes de cuidado" entendidos como las respuestas políticas que ofrece el estado a los cambios que se producen en la familia y el trabajo (Williams y Gavanas, 2008).

Esta aproximación teórica evolucionó en un contexto de fuerte envejecimiento demográfico y de incorporación de las mujeres al mercado laboral. Por ello comenzaron analizando el volumen de los servicios sociales de atención personal dirigidos a los niños y a los adultos mayores y la vinculación entre la inserción laboral femenina y el desarrollo de estos recursos públicos. Entre estas primeras aproximaciones cabe destacar la de Anneli Anttonen y Jorma Sipilä, quienes en 1996, sentaron las bases de esta perspectiva de análisis en la que ya se dibujaban dos focos contrapuestos: Europa del Sur (España, Grecia, Italia y Portugal) caracterizada por un limitado suministro de servicios sociales, donde la mujer se ocupa del bienestar personal de la familia a tiempo completo, y en los que, por tanto, su incorporación al mercado laboral formal es baja; y los países nórdicos (Suecia, Noruega y Finlandia) con una amplia red de servicios públicos y con unas elevadas tasas de inserción laboral femenina.

Avanzando en esta línea de investigación se encuentran los trabajos de Sigrid Leitner (2003) y Francesca Bettio y Janneke Plantenga (2004). Leitner revisa el concepto de familiarización utilizado por Esping-Andersen y efectúa una clasificación a partir de la función de la familia en el cuidado y el papel que juega la protección social en reforzarlo o suavizarlo. Realiza una interesante revisión de las medidas políticas que pueden considerarse familistas como las excedencias para cuidar y las transferencias económicas; y aquellos recursos que mitigan la responsabilidad familiar del cuidado entre los que destaca la importancia de los servicios sociales públicos. Combinando cada uno de estos sistemas identifica cuatro tipos de familismo y encuadra a España en los países de "familismo implícito" caracterizados por una débil red de servicios sociales y de transferencias económicas y, por lo tanto, por una delegación absoluta de la asistencia a la parentela. Esta clasificación coincide con la realizada por Bettio y Plantenga (2004). Ambas autoras descubren analizando los modelos de cuidado en Europa que la insuficiencia de servicios sociales es común en países como Grecia, Italia, Irlanda y España, pero las consecuencias sociales y económicas de esta situación no son uniformes. Así, en el caso de España el resultado es una elevada intensidad del cuidado informal y una escasa incorporación de la mujer en el mundo laboral. En cambio en Portugal, la debilidad de los servicios sociales convive con una alta participación femenina en el mercado de trabajo que se remonta a épocas coloniales, cuando las mujeres reemplazaron en el mercado a los hombres que emigraron a las colonias.

Sin embargo, estos análisis comparativos sobre la fuerza de los servicios sociales, la intensidad del cuidado informal y la tendencia de los programas de protección social hacia la familiarización no eran suficientes para explicar la estrategia de cuidados que se estaba implantando progresivamente en los países de Europa del Sur y en España. El componente de la familia como institución central en la provisión es 
indiscutible pero no observaron como en los últimos años la aceleración de los flujos migratorios a esta región caracterizados por su feminización e irregularidad (Castles y Miller, 1993) modificaron las características esenciales de este régimen de cuidados (Benería, 2008).

El progresivo envejecimiento de la población y el aumento de la participación laboral femenina han provocado la mercantilización del trabajo familiar de cuidados (King y Zontini, 2000) y la inserción de mujeres extranjeras en esta actividad. También han revitalizado la utilización del servicio doméstico como sistema de conciliación familiar entre sexos. Incluso algunos estudios como los efectuados por Sarti (2006) y Platzer (2006) afirman la existencia de una correlación entre la incidencia del servicio doméstico y el gasto social público, de tal forma que los trabajadores domésticos son más numerosos en aquellos países europeos en los que la inversión pública en servicios sociales es menor.

En un principio el vínculo entre inmigración y cuidados aparece en la literatura que analiza los flujos migratorios femeninos como un recurso de los países desarrollados para ocupar aquellos huecos que la inserción laboral de las mujeres autóctonas ha propiciado dentro de los hogares, especialmente las vinculadas al cuidado de niños, enfermos, mayores y discapacitados. Es así como han aparecido recientemente los términos de "criadas de la globalización" ("servants of globalisation") acuñado por Rhacel S. Parreñas (2001), "cadenas globales de cuidado" ("global chains of affection") utilizado por Hochschild (2000), y el de "mujeres globales" para referirse a las inmigrantes ocupadas como niñeras, enfermeras y criadas (Ehrenreich y Hochschild, 2004). Pero todos estos trabajos centrados en el cuidado de niños analizaron la situación de EE.UU. en donde prima una fórmula de estado de bienestar residual por lo que la ausencia de una provisión pública se convertía en el elemento fundamental bajo el que se formaba ese nicho laboral de cuidados en el servicio doméstico.

En Europa, investigaciones que exploran comparativamente las interrelaciones entre los regímenes de cuidados y las migraciones femeninas son las realizadas por Bettio et al. (2006) y Dwan Lyon y Miriam Gluksmann (2008). Estos estudios ofrecen explicaciones multicausales para analizar el recurso de las mujeres inmigrantes en el sector doméstico de cuidados ${ }^{4}$ y más que determinar su aparición por la insuficiencia de servicios sociales adecuados se centran en la influencia de la naturaleza de las políticas sociales públicas. Por ejemplo, coinciden en afirmar que la proliferación de transferencias monetarias directamente gestionadas por las familias que demandan trabajo de cuidados intensivos ha incentivado la contratación de trabajadores domésticos para efectuar estas tareas. Bettio et al. (2006) explica utilizando el caso de Italia como las mujeres inmigrantes están reemplazando en la actualidad el trabajo informal de cuidados de las mujeres autóctonas. Ello ha supuesto un cambio radical en la organización de la atención personal de estos países que han pasado de un modelo

${ }^{4}$ La denominación "sector doméstico de cuidados" hace referencia a las actividades de asistenciales que realizan las empleadas de hogar en el servicio doméstico. 
familiar de cuidados a un modelo de cuidados basado en una "migrante en la familia" (Bettio et al. 2006). Lyon y Gluksmann (2008) utilizando el término "configuraciones de cuidado" en vez de "regímenes de cuidado" examinan la naturaleza de los nexos entre la provisión informal, formal, remunerada y no remunerada y concluyen que efectivamente la configuración del cuidado en Italia y, en general, en los países del sur está centrada en el trabajo de la mano de obra inmigrante en el seno del servicio doméstico.

En España, el campo de investigación en "regímenes de cuidado" todavía no se encuentra desarrollado con plenitud. La inexistencia hasta hace pocos años de una ley estatal destinada a los cuidados de larga duración es una de las causas. Al ser la familia la única fuente de provisión, los estudios se centraron en analizar las características de este apoyo informal. Sin duda, la aplicación de la "Ley de Autonomía y Atención a las Personas en Situación de Dependencia" (LAAD) fomentará nuevas exploraciones en este ámbito. Algunos trabajos a destacar que han analizado la complementariedad entre el régimen de cuidados español y la recepción de mano de obra inmigrante son los realizados por el Colectivo IOÉ (2005), Rogero y Coppola (2009), Marcu (2009) o incluso yo misma (Martínez, 2010), pero todos ellos son anteriores a la LAAD por lo que no han incorporado su impacto en la definición familiar de las estrategias de cuidados. De ahí que este documento tenga como propósito detenerse en las repercusiones de la actual política social en la reestructuración del trabajo familiar de cuidados y en el desarrollo de un sector laboral de asistencia en la economía sumergida. El análisis se centra en la atención de personas mayores y su interés reside en observar cómo se asienta la política estatal de cuidados en cada contexto regional para destapar las diferencias territoriales que empaña la dimensión nacional. Las medidas de protección social, tanto en su fórmula de servicios sociales como de transferencias monetarias y la intensidad del cuidado familiar son los principales ámbitos en los que se estudian las divergencias.

\section{Más externalización y similar desequilibrio en el reparto familiar del trabajo de cuidados}

La ayuda familiar es un soporte esencial en la provisión del cuidado pero la relevante implicación de los parientes no suele coexistir con una red pública de servicios sociales. Entre los mayores de 65 años, la parentela es cuidadora principal en el $85,3 \%$ de aquellos que reciben asistencia personal. Los servicios públicos de atención únicamente proveen cuidados al $5,9 \%$ de los adultos mayores con dependencia y solamente son asistentes principales en el 2,9\% de los casos. Y a la insuficiencia en la cobertura se une la necesidad de complementar los programas de rehabilitación con una red de apoyo informal que permita su adecuado desarrollo. De ahí que en el $88,7 \%$ de los casos los cuidadores residen y son miembros del hogar del receptor de la atención, cifra que demuestra la capacidad de los vínculos de parentesco en el mantenimiento de la asistencia (ver tabla 1). 
Tabla 1.- Residencia de las personas que prestan cuidados

\begin{tabular}{lcc} 
& Total & $\begin{array}{c}\text { Mayores 65 } \\
\text { años }\end{array}$ \\
\hline Residen en el hogar y son miembros del mismo & 73,5 & 88,7 \\
En el hogar y son personas empleadas & 3,8 & 6,4 \\
Fuera del hogar & 21,1 & 3,2 \\
No consta & 1,6 & 1,7
\end{tabular}

Fuente: Elaboración propia. Explotación microdatos de INE, EDAD 2008.

Al igual que ya habían puesto en evidencia anteriores investigaciones (IMSERSO, 2004a; INE, 2002; Durán, 2006; Tobío et al., 2010) recientes datos (INE, 2009) muestran cómo la responsabilidad de los cuidados sigue recayendo entre los cónyuges y las hijas confirmándose la jerarquía en la dispensación de atención según generación y sexo dentro de la parentela. Éstas últimas atienden al 38,1\% de los adultos mayores y este porcentaje se incrementa hasta el $43,3 \%$ cuando el receptor de los cuidados es una mujer. Si la persona a cuidar es un hombre la asistencia es desempeñada por la esposa $(46,6 \%)$ (ver tabla 2). Ello se traduce en que el $76,0 \%$ de los cuidadores principales sean mujeres y que tres de cada cuatro tenga más de 45 años. En su mayoría no forman parte del mercado formal: el 17,0\% declaran estar cobrando una pensión de jubilación y el 20,9\% se dedican a las tareas del hogar (INE, 2009). Es decir, mientras existan generaciones de mujeres alejadas de la participación laboral se mantiene este sistema de cuidados con escasa incidencia de los servicios sociales públicos ya que continúa la mínima atribución de tareas a los miembros masculinos del hogar. El porcentaje de maridos cuidadores se sitúa en un $15,5 \%$, el de los hijos en un $9,0 \%$ y el de los hermanos es insignificante $(0,5 \%)$. 
Tabla 2.- Personas mayores de 65 años con alguna discapacidad que reciben asistencia personal según relación con el cuidador principal

\begin{tabular}{l|cc|cc|cc} 
& \multicolumn{2}{|c|}{ TOTAL } & \multicolumn{2}{c|}{ HOMBRES } & \multicolumn{2}{c}{ MUJERES } \\
& $\mathrm{n}$ & $\%$ & $\mathrm{n}$ & $\%$ & $\mathrm{n}$ & $\%$ \\
\hline TOTAL & 1400,3 & & 405,6 & & 994,7 & \\
Subtotal & 1132,4 & 100,0 & 335,7 & 100,0 & 796,6 & 100,0 \\
& & & & & & \\
Cónyuge o pareja & 279,9 & 24,7 & 156,6 & 46,6 & 123,3 & 15,5 \\
Hija & 430,9 & 38,1 & 86,2 & 25,7 & 344,7 & 43,3 \\
Hijo & 101,9 & 9,0 & 22,4 & 6,7 & 79,5 & 10,0 \\
Hermana & 26,5 & 2,3 & 11,2 & 3,3 & 15,4 & 1,9 \\
Hermano & 5,3 & 0,5 & 2 & 0,6 & 3,3 & 0,4 \\
Otro pariente & 121,6 & 10,7 & 25,5 & 7,6 & 96,2 & 12,1 \\
Empleado & 117,4 & 10,4 & 24,7 & 7,4 & 92,7 & 11,6 \\
Servicios sociales & & & & & & \\
(AAPP, ONG) & 32,8 & 2,9 & 3,8 & 1,1 & 29 & 3,6 \\
Amigos y vecinos & 4,8 & 0,4 & 0,5 & 0,1 & 4,4 & 0,6 \\
Otras personas & 11,1 & 1,0 & 2,9 & 0,9 & 8,3 & 1,0 \\
No consta & 267,9 & & 69,9 & & 198,1 &
\end{tabular}

Fuente: Elaboración propia. Explotación microdatos de INE, EDAD 2008.

La organización de los cuidados no ha cambiado en los últimos años. La familia, y dentro de ella las mujeres, continúan siendo las protagonistas. La única reestructuración que se advierte en la provisión de la asistencia es la que aparece cuando se decide mercantilizar esta tarea y de entre todas las opciones existentes (residencias, empresas privadas...) la preferida es el servicio doméstico. Ya en el año 2004 una encuesta realizada por el IMSERSO titulada "Apoyo informal a personas mayores" (IMSERSO, 2004a) informaba de que el 7,0\% de las personas de edad recibían asistencia de una empleada de hogar. Dos años más tarde, la "Encuesta sobre Condiciones de Vida de las Personas Mayores" (Abellán et al., 2007) estimaba su repercusión en el $10,0 \%$, cálculo que coincide con el proporcionado por la fuente de datos más reciente, la Encuesta EDAD 2008 (INE, 2009), que contabiliza a las cuidadoras domésticas como el 10,4\% de los asistentes principales entre los mayores. Y esta cifra alcanza el $14,5 \%$ si se tienen en cuenta a los cuidadores de hogar secundarios (ver gráfico 1). 


\section{Gráfico 1.- Tipo de ayuda asistencial que reciben los mayores con dependencia según diversas fuentes de información}

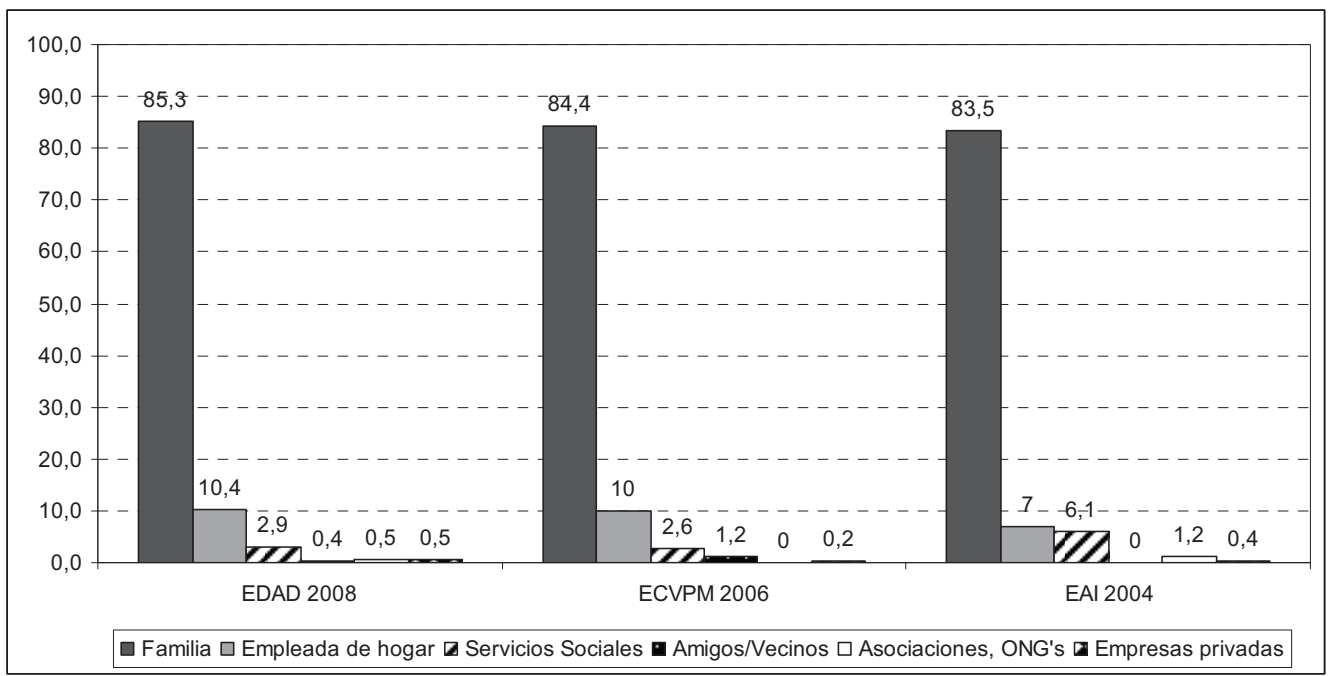

Fuente: Elaboración propia. Explotación microdatos de INE, EDAD 2008; de IMSERSO 2006, Encuesta de Condiciones de vida de las personas mayores; IMSERSO 2004a, Encuesta Apoyo Informal.

Una cultura del cuidado fuertemente familista, una protección social débil y reforzadora de la parentela como proveedora, y una escasa asunción de responsabilidades domésticas por parte de los hombres han repercutido en la aparición de una estrategia de externalización individualista pensada desde y para la familia. La reorganización de los cuidados se centra en los recursos que ofrece el mercado privado y no pasa ni por un reparto más adecuado de las tareas entre hombres y mujeres (mitigando así la división sexual y generacional de estas labores) ni por una reivindicación de mejorar la protección social.

Se aprecia una tendencia al alza en la privatización que si bien es todavía escasa (debido a la alta participación de la familia en los cuidados) ha tenido un relevante impacto en la estructura del servicio doméstico. El incremento de empleadas de hogar ya se viene produciendo desde los años noventa, década en la que dicha demanda comienza a incidir en la extranjerización del sector. A comienzos del siglo XXI y a raíz de las sucesivas regularizaciones extraordinarias este proceso se acentúa: en la Normalización del año 2005 algo más de 180.000 solicitudes se concedieron al Régimen de Hogar, lo que supuso que en casi tres de cada cuatro casos la normalización del empleo femenino extranjero se correspondió con el servicio doméstico. A finales del 2009 los datos de afiliación a la Seguridad Social ofrecidos por el Ministerio de Trabajo muestran que el 60,6\% de las personas incluidas en el Régimen Especial de Empleadas de Hogar son extranjeras, cuando en el año 2000 esta cifra era de un $31,8 \%$. 
Al mismo tiempo que aumenta el número de familias empleadoras que requieren la contratación de asistentas para desempeñar trabajos de cuidados, esta actividad se consolida como un nicho laboral para las mujeres inmigrantes. Algunos estudios han señalado que el servicio doméstico, y principalmente el destinado a los cuidados personales, se ha convertido en el inicio de la trayectoria laboral de las mujeres inmigrantes en España y ya hay ONG's que estiman que el $90 \%$ de las ofertas laborales que reciben están relacionadas con este sector (IMSERSO, 2005; Martínez, 2010). La demanda ha sido tan relevante, a pesar de la mínima privatización, que en los últimos tres años de fuerte crisis económica el único régimen de actividad que no ha perdido efectivos ha sido el de Empleados de Hogar. Del año 2007 al año 2008, aumentó un $6,4 \%$ su número de trabajadores, y a pesar de que su crecimiento ha sido más pausado en el período 2008-2009, todavía presenta valores positivos (un 1,1\%) (ver gráfico 2). Y la tendencia continúa si se desciende al nivel de ramas de actividad: los hogares que emplean personal doméstico han crecido un 1,6\% del 2007 al 2008 y un 3,1\% en la variación anual 08/09. Las actividades con mejor comportamiento económico desde el estallido de la crisis son aquellas relacionadas con los servicios públicos como los que concentran las "actividades sanitarias" que en el momento de mayor recesión (del año 2007 al 2008) aumentaron el número de afiliados en un 7,4\% (ver tabla 3$)$.

La preferencia de las familias por la contratación de cuidadoras en el seno del servicio doméstico está en gran parte determinada por las características laborales de este sector que permiten una mayor flexibilización de horarios, una adecuación entre el tiempo de atención y el desarrollo de las tareas domésticas y la presencia, mediante la "modalidad de interna", de una cuidadora permanente que esté pendiente de las necesidades del mayor durante 24 horas diarias. 
Gráfico 2.- Variación de afiliados en alta laboral a la Seguridad Social según régimen, 2007-2009

(en miles de personas en media mensual y variación en porcentaje)

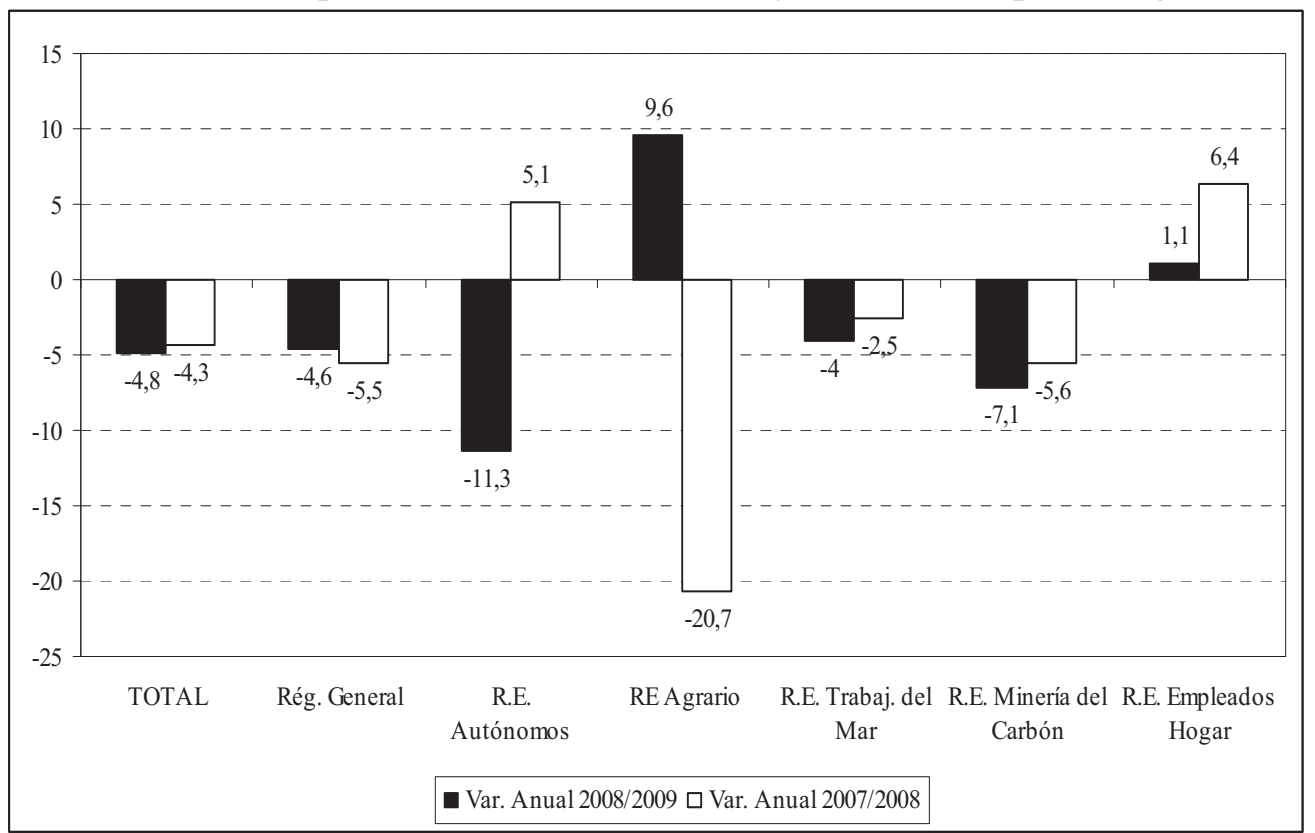

Fuente: Elaboración propia a partir de CES, 2009 y MTIN, Afiliaciones en Alta Laboral. * El 1 de enero de 2008 se produce un traspaso de los trabajadores agrarios por cuenta propia al Régimen Especial de Trabajadores Autónomos, de acuerdo a lo establecido en la Ley 18/2007 de 4 de julio, de ahí que se haya experimentado una caída del 20,7\% y que el RE de Autónomos a pesar de ser uno de los más castigados por la crisis haya crecido un 5,1\% (CES, 2009). 
Tabla 3.- Afiliados en alta laboral a la Seguridad Social (en miles de personas en media mensual y variación en porcentaje)

\begin{tabular}{|l|c|c|}
\hline \multicolumn{1}{|c|}{ Ramas de actividad $^{\mathbf{5}}$} & Var. Anual 2008/2009 & $\begin{array}{c}\text { Var. Anual } \\
2007 / 2008\end{array}$ \\
\hline $\begin{array}{l}\text { Agricultura, ganadería, caza, pesca } \\
\text { y silvicultura }\end{array}$ & $-15,7$ & 135,5 \\
\hline Industrias extractivas & $-11,0$ & $-12,2$ \\
\hline Industria manufacturera & $-13,1$ & $-7,1$ \\
\hline Producción de energía & 0,0 & 1,6 \\
\hline Construcción & $-17,1$ & $-22,0$ \\
\hline Comercio. Reparación de vehículos a motor & $-8,2$ & $-3,9$ \\
\hline Hostelería & $-2,2$ & $-1,7$ \\
\hline $\begin{array}{l}\text { Transporte. Almacenamiento } \\
\text { y comunicaciones }\end{array}$ & $-19,0$ & $-2,9$ \\
\hline Instituciones financieras y seguros & $-1,9$ & 0,3 \\
\hline $\begin{array}{l}\text { Actividades inmobiliarias y de alquiler; S.S. } \\
\text { empresariales }\end{array}$ & 0,0 & $-4,4$ \\
\hline $\begin{array}{l}\text { Admón. pública, defensa y S. Social } \\
\text { obligatoria }\end{array}$ & $\mathbf{3 , 0}$ & 1,5 \\
\hline Educación & $-0,8$ & 3,7 \\
\hline $\begin{array}{l}\text { Actividades sanitarias y veterinarias. Servicios } \\
\text { Sociales }\end{array}$ & 0 & $\mathbf{7 , 4}$ \\
\hline $\begin{array}{l}\text { Otras actividades sociales. Servicios } \\
\text { Personales }\end{array}$ & 0,0 & $-0,3$ \\
\hline Hogares que emplean personal doméstico & $\mathbf{3 , 1}$ & 1,1 \\
\hline Organismos extraterritoriales & 8,7 & 9,0 \\
\hline
\end{tabular}

Fuente: Elaboración propia a partir de CES, 2009 y MTIN, Afiliaciones en Alta Laboral.

${ }^{5}$ Todas las categorías de actividad que puntúan cero en el 2009 se debe a un cambio en la clasificación de las ramas de actividad que se produce en ese año. 
La oferta de provisión de cuidados por empresas privadas tiene un coste económico tan elevado que pocos presupuestos familiares pueden soportarlo. Además, la frecuencia y el tiempo de asistencia que ofrecen no alcanzan a cubrir las necesidades de la población dependiente. El tiempo medio de atención diario suministrado por las familias es de siete horas, el $89,6 \%$ se dedica a estas tareas al menos 6 ó 7 días a la semana y en el 34,4\% la duración del cuidado se extiende durante más de ocho años. El cuidado que presta la red familiar se caracteriza por no ser ocasional, existir afectividad en la relación y un grado de compromiso que implica permanencia (IEA, 2008), de ahí que la familia busque una cuidadora que dispense este tipo de asistencia continúa y cargada de afecto.

Las familias empleadoras requieren una persona que realice tareas más allá de la atención personal al mayor que incluyen el componente emocional de ofrecer bienestar y cariño simplemente con su compañía. Las empresas privadas que funcionan bajo la lógica de la burocratización y de la impersonalización sólo se dedican a labores profesionales (Glenn, 2000). Las mayores relaciones de dominación y explotación que pueden realizarse dentro del dominio privado también pueden ser observadas como ventajas (Ungerson, 99).

Este desarrollo de las tareas asistenciales dentro del servicio doméstico ha supuesto por una parte, la revitalización de la figura de doméstica interna, régimen que en la década de los noventa había empezado a disminuir (Martínez, 2000). Los datos de la Encuesta EDAD 2008 muestran que el 3,8\% de los cuidadores residentes son personas empleadas de hogar y esta cifra aumenta a un $6,4 \%$ si la persona que recibe atención es mayor de 65 años (ver tabla 1). En 1999, la Encuesta EDDES, recogía que los empleados de hogar que convivían con los mayores a los que asistían eran de un $0,9 \%$ (INE, 2002). Pero por otra, también ha significado la aparición de nuevas formas de empleo inexistentes en el servicio doméstico tradicional. A la modalidad de convivencia de la que formaría parte la figura de interna habría que añadir otras relacionadas con la "asistencia" y la "compañía" al aparecer empleos eventuales para los fines de semana, algunas noches o determinadas horas para sacar a pasear al mayor (Martínez, 2006). Modalidades ausentes de regulación legal pues el Real Decreto 1424/1985 sobre el servicio doméstico únicamente reconoce los regímenes interno y externo.

Las mujeres foráneas se encuentran en los empleos de cuidado que requieren jornadas laborales más extenuantes y las españolas se ubican en los trabajos asistenciales de menor intensidad y más profesionalizados (Vega, 2009). Incluso dentro del empleo de hogar, las modalidades de asistencia en las que predomina la dureza del trabajo, la ausencia de días libres y el escaso salario son abastecidas principalmente por las mujeres extranjeras. Se calcula que alrededor del $80 \%$ de las trabajadoras internas son inmigrantes y su prevalencia entre los empleos de cuidado por horas es tan sólo del 20\% (IMSERSO, 2004b). Los datos de la Encuesta de Población Activa para el segundo trimestre del 2009 muestran además como la incidencia de trabajadores extranjeros ocupados en trabajos de cuidados profesionales, recogidos en la categoría de "Actividades Asistenciales y Servicios Sociales", es del 14,6\% mientras que su presencia en el ámbito del servicio doméstico es del $60,4 \%$. 
De esta forma, se puede afirmar que la manera en la que se están reorganizando los cuidados familiares profundiza en la división entre un mercado formal caracterizado por la definición legal de las remuneraciones y por la contratación profesional de trabajadoras nativas y un mercado informal basado en el establecimiento de las condiciones laborales de manera particular entre el empleador y el trabajador, que emplea mujeres inmigrantes sin formación en el ámbito de cuidados y en situación irregular. De hecho, el 74,3\% de las cuidadoras empleadas de hogar afirman que es la primera vez que trabajan en este sector de actividad y el 34,6\% declara que si cambiara de empleo se dedicaría a otro sector (INE, 2009). La necesidad de encontrar un trabajo cuánto antes tras su llegada a España y el difícil acceso a la regularidad jurídica si no se está inserto en el mercado laboral motiva la aceptación de cualquier tipo de empleo.

\section{El fomento del sector doméstico de cuidados desde las prestaciones económicas}

La Ley 39/2006 de Promoción de la Autonomía Personal y Atención a las Personas en situación de Dependencia se ha convertido en el principal instrumento de transformación de la filosofía del régimen de cuidados español influyendo en la consolidación del sector doméstico de cuidados como principal opción de externalización. La insuficiencia de los servicios sociales y la ausencia de una política social estatal que enmarcarse las actuaciones autonómicas modelaron un sistema de atención fuertemente familista cuyas funciones de cuidados no se reforzaban por ninguna política social concreta, sino por la ausencia absoluta de la misma. Este modelo denominado como "familismo implícito" (Leitner, 2003) comenzará a modificarse con la aprobación de la LAAD porque instaura un nivel básico de protección a la dependencia, implanta una cobertura social independientemente de la edad y de la actividad laboral ejercida y, sobre todo, porque introduce nuevas medidas de atención a los cuidados personales tanto en materia de servicios sociales como de prestaciones económicas.

En cuanto a los servicios sociales prevé una ampliación de los ya existentes (Servicio de Ayuda a Domicilio, Teleasistencia, Centros de Día y Residencias Gerontológicas) pero poco modifica su estructura ya que dependerá de los gobiernos autonómicos la forma en la que se apliquen cada uno de estos recursos. Más llamativo y mediático, por su inexistencia anterior, es la implantación de una serie de transferencias monetarias destinadas a la compra de cuidados personales y a la compensación del trabajo asistencial familiar. Con anterioridad a la ley este tipo de prestaciones estaban muy poco extendidas ya que la propia filosofía de la protección social en España impedía su evolución. Al medirse la ausencia de autonomía a partir de la "incapacidad para desempeñar un empleo" la protección social únicamente actuaba cuando la persona con diversidad funcional estaba en edad activa. De esta manera, las pensiones para cubrir estados de dependencia se asociaban a las propias pensiones de incapacidad. Por ello, estas nuevas modalidades de ayudas económicas van a repercutir principalmente en la reorganización de los cuidados dirigidos a las personas mayores. 
En concreto, se han programado tres medidas monetarias destinadas respectivamente a la adquisición de servicios de atención proporcionados por empresas privadas, a la contratación de un asistente personal o a la remuneración de un familiar o cuidador no profesional que se dedique a estas tareas (ver con detalle en la tabla 4). Ésta última ha sido la más potenciada de entre todos los recursos previstos. Los datos del "Instituto de Mayores y Servicios Sociales" indican que la prestación económica para "Cuidados en el entorno familiar y apoyo a cuidadores no profesionales" concentra al $50,0 \%$ (ver tabla 5) de los usuarios del Sistema Nacional de la Dependencia (SND) ${ }^{6}$ y ello a pesar de que la propia ley destacaba el carácter prioritario de los servicios sociales sobre los subsidios, considerados éstos como una medida excepcional a conceder exclusivamente en ausencia de servicios sociales en el entorno del usuario.

\section{Tabla 4.- Catálogo de prestaciones económicas de la Ley 39/2006}

Prestación económica vinculada al servicio. Se otorgará en aquellos casos en los que "no sea posible el acceso a un servicio público o concertado de atención y cuidado, en función del grado y nivel de dependencia y de la capacidad económica del beneficiario". Esta prestación estará vinculada a la adquisición de un servicio social privado (artículo 17, Ley 39/2006).

Prestación económica para cuidados en el entorno familiar y apoyo a cuidadores no profesionales. Se reconocerá "excepcionalmente cuando el beneficiario esté siendo atendido por su entorno familiar" y se reúnan unas determinadas condiciones de convivencia y habitabilidad de la vivienda. "El cuidador deberá ajustarse a las normas de afiliación, alta y cotización a la Seguridad Social". Asimismo, se incorporarán acciones de apoyo a los cuidadores no profesionales entre las cuales estarán "programas de formación, información y medidas para atender los períodos de descanso" (artículo 18, Ley 39/2006).

Prestación económica de asistencia personal. Su finalidad es "la promoción de la autonomía de las personas con gran dependencia. Su objetivo es contribuir a la contratación de una asistencia persona, durante un número de horas, que facilite al beneficiario el acceso a la educación y al trabajo, así como una vida más autónoma en el ejercicio de las actividades básicas de la vida diaria" (artículo 19, Ley 39/2006).

Fuente: Elaboración propia

${ }^{6}$ El Servicio Nacional de Dependencia (SND) se configura como una red de utilización pública que integra de forma coordinada centros y servicios públicos y privados de atención a la dependencia. Su financiación correrá a cargo de la Administración General del Estado, las Comunidades Autónomas y las Entidades Locales. 
Tabla 5.- Prestaciones reconocidas mediante la Ley 39/2006 (a 31 de diciembre de 2009)

\begin{tabular}{|l|c|c|}
\hline PRESTACIONES & Beneficiarios & Porcentaje \\
\hline TOTAL & 560.530 & 100,0 \\
\hline $\begin{array}{l}\text { Prevención, dependencia y promoción de la } \\
\text { autonomía personal }\end{array}$ & 3.018 & 0,5 \\
\hline Teleasistencia & 51.480 & 9,2 \\
\hline Ayuda a Domicilio & 59.476 & 10,6 \\
\hline Centros de Día/Noche & 28.479 & 5,1 \\
\hline Atención residencial & 98.941 & 17,7 \\
\hline PE vinculada al servicio & 38.158 & 6,8 \\
\hline PE cuidados familiares y no profesionales & 280.013 & 50,0 \\
\hline PE asistencia personal & 685 & 0,1 \\
\hline
\end{tabular}

Fuente: IMSERSO, Servicio de Estadísticas de la Subdirección General Adjunta de Valoración, Calidad y Evaluación.

Aunque esta prestación contempla la posibilidad de externalizar la asistencia en cuidadores no profesionales lo cierto es que la mayor parte de la misma se ha destinado a familiares. Ello es debido a que son los parientes los principales cuidadores pero también impuestas por esta modalidad para la contratación de ayuda externa. Por una parte, la legislación incide en que los cuidadores no profesionales contratados deben ser personas que se hayan dedicado al cuidado del dependiente durante al menos un período previo de un año y que éste viva en una localidad de difícil acceso a otros servicios públicos.

Pero, no se contempla cómo tiene que acreditarse ese tiempo de cuidados, siendo el trabajador social (al que corresponde evaluar el grado de dependencia y la concesión de la ayuda), la persona que certifica el cumplimiento de este criterio. Por otra parte, también se insiste en que los cuidadores se incluirán en la Seguridad Social en "situación asimilada al alta, mediante la suscripción a un convenido especial" (Real Decreto 615/2007) pero si en el entorno no existen alternativas formales de cuidados externas a la familia y si las únicas personas dispuestas a desempeñar este trabajo son mujeres inmigrantes en situación irregular no es factible su incorporación a la Seguridad Social.

Si bien es loable la intención de regularizar la situación de las personas contratadas y de las cuidadoras familiares con un convenio específico, la validez del sistema se ve cuestionada por:

- la inexistencia de un convenio colectivo que regularice las condiciones laborales (vacaciones, pagas extraordinarias, horario de trabajo...) 
- el no reconocimiento a percibir algunas prestaciones básicas como la de desempleo o la de maternidad (la cotización solo sirve para la pensión de jubilación y de incapacidad permanente);

- la escasez de la cuantía de la prestación que en el año 2007 varía entre los 487 y los 390 euros mensuales según el grado de dependencia de la persona a cuidar situándose por debajo del Salario Mínimo Interprofesional establecido en $633,3 € /$ mes (en el año 2010).

La postura gubernamental y los efectos de la LAAD son contradictorios: se reconoce que los hogares no pueden seguir en soledad con estas tareas pero también reafirma el papel de la mujer familiar cuidadora y silencia la figura que la empleada de hogar está adquiriendo en el régimen de cuidados español. Tal es el caso, que en Navarra, región a la que he podido tener acceso a la configuración de este sistema, la administración ya comienza a percibir que algunas familias utilizan ese salario mensual para contratar mujeres inmigrantes en el servicio doméstico para que realicen las tareas de cuidado. Debido a la dificultad de justificar el tiempo de un año de cuidados no profesionales desempeñados por una empleada de hogar y además como en muchas ocasiones se trata de personas en situación irregular y, por tanto, no pueden darse de alta en la Seguridad Social como establece la ley, la estrategia es solicitar la ayuda económica por "cuidados familiares" e invertirla en la contratación de una cuidadora doméstica. De ello se deriva que, a pesar del sigilo gubernamental en torno a este aspecto, la política de subsidios monetarios llega a financiar ese sector sumergido de cuidados dentro del servicio doméstico ${ }^{7}$.

Es más, en las comunidades en las que las prestaciones del SND están más desequilibradas a favor de los subsidios monetarios para "cuidados familiares" coinciden con aquellas en las que la utilización de empleadas de hogar como cuidadoras es más elevada. Si combinamos los datos del IMSERSO referentes a las prestaciones otorgadas por la ley junto con los de la Encuesta EDAD 2008 que recogen el porcentaje de personas atendidas mediante el servicio doméstico obtenemos la información presentada en la tabla 6. Así sucede en los casos de Murcia, donde el 82,0\% de los usuarios

${ }^{7}$ Esta situación es incluso reconocida por el grupo de expertos que ha realizado el primer "Informe final para la evaluación del desarrollo y efectiva aplicación de la ley 39/2006" (VV.AA., 2009), en donde se detalla que: "Es oportuno hacer aflorar la ocupación irregular a la que en la mayoría de los casos se remunera con la prestación familiar, con incentivos de formación y contratación de personas en situación de paro del sector servicios. Un plan con medidas específicas a tal fin debe permitir la mejora de las condiciones de trabajo y el reconocimiento oficial de los cuidadores informales en los sistemas de seguridad social, una vez homologada su situación. Ignorar esta realidad es dar la espalda a algo que cada vez se extiende más: la atención a las personas dependientes en el hogar a través de cuidadores sin contrato y con nula o muy baja formación". 
del SND reciben la mencionada subvención y el $17,6 \%$ de los mayores con dependencia reciben cuidados de una empleada de hogar, Baleares donde el porcentaje de la subvención se sitúa en el 66,9\% y la asistencia del servicio doméstico asciende a un $21,2 \%$ y en Navarra con un peso del $66,7 \%$ de la prestación económica y un $24,8 \%$ de cobertura de la atención personal desempeñada por empleadas de hogar.

Tabla 6.- Incidencia del servicio doméstico en los cuidados a personas mayores y prevalencia de la PE “Cuidados Familiares" sobre el total de usuarios del SND

\begin{tabular}{|l|c|c|}
\hline & $\begin{array}{c}\text { Personas mayores cuidadas } \\
\text { por empleadas de hogar* }\end{array}$ & $\begin{array}{c}\text { Peso de la PE “Cuidados familiares" } \\
\text { sobre el total de beneficiarios del SND }\end{array}$ \\
\hline Total & 14,5 & 50,0 \\
\hline Andalucía & 10,3 & 46,4 \\
\hline Aragón & 16,9 & 65,3 \\
\hline Asturias & 14,5 & 47,7 \\
\hline Balears & $\mathbf{2 1 , 2}$ & $\mathbf{6 6 , 9}$ \\
\hline Canarias & 6,8 & 53,5 \\
\hline Cantabria & 15,4 & 62,8 \\
\hline Castilla y & & \\
León & 13,2 & 40,3 \\
\hline Castilla-La & 14,2 & 55,0 \\
\hline Mancha & 13,1 & 58,9 \\
\hline Cataluña & 17,8 & 53,8 \\
\hline C. Valenciana & 14,0 & 41,3 \\
\hline Extremadura & 11,1 & 58,8 \\
\hline Galicia & 17,0 & 19,1 \\
\hline Madrid & $\mathbf{1 7 , 6}$ & $\mathbf{8 2 , 0}$ \\
\hline Murcia & $\mathbf{2 4 , 8}$ & $\mathbf{6 6 , 7}$ \\
\hline Navarra & 26,1 & 40,9 \\
\hline País Vasco & 22,2 & 44,4 \\
\hline La Rioja & . & \\
\hline
\end{tabular}

Fuente: IMSERSO (2010), Servicio de Estadísticas de la Subdirección General Adjunta de Valoración, Calidad y Evaluación; INE (2009), EDAD 2008; * Se ha calculado a partir del número de personas mayores que han contratado una empleada de hogar como cuidadora entre el total de mayores con dependencia.

\section{Las variedades del familismo a escala regional}

Sin embargo, el grado de familismo y de mercantilización de la asistencia no puede medirse únicamente a partir del desarrollo de una política social con tendencia a las transferencias económicas. En La Rioja y en el País Vasco, por ejemplo, la figura 
de la cuidadora doméstica es elevada a pesar del escaso desarrollo de los subsidios monetarios. Éstos pueden influir pero los dispositivos que se activan para el cuidado también están relacionados con otros aspectos del entorno como el modelo migratorio, la participación laboral femenina o la cultura de cuidados. Si se observan cada uno de estos factores a nivel regional puede estudiarse con más detalle como se establecen las responsabilidades del cuidado y como se utilizan los recursos familiares, estatales y mercantiles en la atención personal. Para avanzar en este terreno se ha diseñado la tabla 8. En ese cuadro aparecen representadas cada una de las comunidades autónomas con respecto a una serie de variables que determinan el peso del apoyo informal, la extensión de los servicios sociales y el grado de desarrollo del sector doméstico de cuidados para la atención de personas mayores. Es decir, se recogen todas las entidades que participan en la asistencia.

El cuidado familiar se ha medido como el porcentaje de hogares con personas de edad dependientes que solamente reciben atención familiar. La capacidad del estado en el suministro de cuidados se ha contabilizado a partir de la cobertura de los servicios sociales y de las transferencias económicas, usando como unidad analítica en el primer caso la cobertura del servicio de ayuda a domicilio (SAD) y en el segundo la cobertura de la prestación por "Cuidados Familiares" sobre el total de adultos mayores dependientes. Por último, el nivel de desarrollo del mercado privado de cuidados se ha ejemplificado en el porcentaje de mayores con dependencia que han contratado una empleada de hogar para las tareas asistenciales.

La manera en que se combinan las diferentes formas de provisión de cuidados en cada una de las comunidades autónomas es un reflejo de las diversas concepciones de las políticas sociales a escala regional. El mapa heterogéneo de prestaciones y de culturas familiares del cuidado introduce modelos diversos de atención que circulan desde las opciones más profesionalizadas, las centradas en los trabajos de los servicios sociales, a otras más domésticas, que destacan por la utilización más asidua de empleadas de hogar. La característica común en todos los casos es el papel protagonista de la familia. Siguiendo las puntuaciones regionales en cada uno de los indicadores establecidos se observan las siguientes tendencias:

1) Un modelo que se caracteriza por ser la familia la agencia principal de cuidados pero cuya labor asistencial es apoyada por la administración pública a través de los servicios sociales y las transferencias económicas de gestión directa. Como el fomento de ambos recursos no es equilibrado, dentro de este régimen "familista con apoyo público" se distinguen dos alternativas:

a) Los contextos en los que el soporte público se centra en las prestaciones económicas. Se incluyen en esta categoría "familista subvencionada", Andalucía, Aragón y Cantabria. La cobertura de los subsidios es muy elevada, varía entre un 30 y un $37 \%$ de la población mayor con dependencia (cuando la media nacional es de un 20,0\%), y se combina con la existencia de un importante papel familiar en los cuidados. El caso más representativo es Andalucía en donde el $84 \%$ de los mayores dependientes son cuidados exclusivamente por su familia y donde las transferencias monetarias alcanzan al 33,6\% de es- 
te colectivo. En estos casos, la consecuencia de la financiación directa es el refuerzo de las responsabilidades familiares.

b) Los lugares en los que la política social ha promocionado la extensión del servicio de ayuda a domicilio formando parte de este nivel las comunidades de Madrid, Extremadura, Castilla La Mancha, Cataluña, Castilla y León y Asturias. A este modelo le podemos denominar como "familista profesional" y presenta diferentes desarrollos en cada una de las autonomías mencionadas. Por ejemplo, el SAD más amplio se encuentra en Madrid con un 54,8\% de mayores con dependencia que cuentan con este servicio. En esta comunidad, las prestaciones económicas únicamente cubren al 4,0\% del colectivo y la implicación familiar es bastante elevada, de manera que, los servicios profesionales no han defamiliarizado los cuidados.

2) Aparecen un grupo de regiones en los que resalta la externalización de los cuidados por encima de la provisión estatal. En esta pauta, que puede clasificarse como "modelo doméstico", la contratación de empleadas de hogar puede producirse por dos causas:

a) Por la inexistencia de una protección social pública, siendo ésta la situación en Baleares y Valencia en donde la cobertura del SAD está por debajo de la media estatal $(25,6 \%)$. Las prestaciones económicas también son muy escasas, cubriendo a un $8,4 \%$ de la población adulta mayor dependiente en la C. Valenciana y un $17,0 \%$ en Baleares. Destaca la provisión de cuidados por medio de empleadas de hogar, siendo el porcentaje de cuidadores domésticos de un $21,2 \%$ en Baleares y de un 17,8\% en el caso valenciano. Es el "modelo doméstico no facilitado públicamente".

b) Por la existencia de una política social orientada a la concesión de prestaciones económicas otorgadas a los cuidadores directamente o para la contratación de asistentes no cualificados. Este proceso de externalización subvencionada tiene lugar en Navarra y Murcia, lugares en los que las ayudas económicas públicas de cuidados y el sector doméstico cubren a una cantidad similar de personas mayores. Este proceso obtiene en estas regiones entre las puntuaciones más elevadas de todo el país. Así, en el caso de la Comunidad Foral, el porcentaje de empleadas de hogar cuidadoras es del $24,8 \%$ y la cobertura de los subsidios se sitúa en el 28,7\%.

3) Una tercera vía de provisión es la que se establece en La Rioja y el País Vasco. Estas regiones acogen la situación más equilibrada de provisión con una elevada participación de los servicios sociales, las prestaciones económicas, la contratación de servicio doméstico y la atención familiar, de ahí que pueda denominarse como "modelo opcional" (Leitner, 2003). Resalta el hecho de que poseen una amplia protección social que lejos de inhibir la demanda de cuidadoras en el régimen doméstico como la lógica podría indicar, representan los porcentajes más elevados de contratación de empleadas de hogar. En el caso del País Vasco este peso es del 26,0\% y en el de La 
Rioja es del $22,2 \%$, superando ampliamente el $14,5 \%$ de la media estatal. El mayor grado de bienestar social potencia este mercado laboral de cuidados en el servicio doméstico.

4) En todos los contextos autonómicos se ha encontrado el desarrollo de algún tipo de política social conducente a suavizar la carga de cuidados familiares. Sin embargo, y a pesar de la ampliación generalizada de los servicios sociales en los últimos años, existen regiones en las que los cuidados familiares conviven con una mínima extensión de otras formas de provisión tanto públicas como privadas. Son los casos de Galicia y Canarias, en los que la asistencia recae fundamentalmente en la parentela y cuyo modelo puede denominarse como "familista absoluto" al no existir alternativas ni públicas ni privadas. En Galicia la cobertura del SAD es del 8,1\%, la de las transferencias del $14,5 \%$ y la incidencia del sector doméstico de cuidados es tan sólo del $11,1 \%$. Ello deriva en que las familias cuiden aisladamente en el $82,6 \%$ de los casos.

Tabla 6.- Clasificación de las estrategias de cuidado para las personas mayores en España

\begin{tabular}{|c|c|c|c|}
\hline \multicolumn{2}{|c|}{ DENOMINACIÓN } & CONTEXTOS & CARACTERÍSTICAS \\
\hline \multirow{2}{*}{$\begin{array}{l}\text { Régimen } \\
\text { familista con } \\
\text { apoyo } \\
\text { público }\end{array}$} & Profesionalizado & $\begin{array}{l}\text { Madrid, Extremadu- } \\
\text { ra, Castilla La } \\
\text { Mancha. } \\
\text { Cataluña, Castilla y } \\
\text { León y Asturias }\end{array}$ & $\begin{array}{l}\text { Entre los elementos de } \\
\text { provisión externa a la } \\
\text { familia predomina la } \\
\text { extensión del servicio de } \\
\text { ayuda a domicilio }\end{array}$ \\
\hline & Subvencionado & $\begin{array}{c}\text { Andalucía, Aragón y } \\
\text { Cantabria }\end{array}$ & $\begin{array}{l}\text { El cuidado familiar es } \\
\text { apoyado mediante subven- } \\
\text { ciones económicas. El } \\
\text { mercado privado del } \\
\text { servicio doméstico no está } \\
\text { muy desarrollado. }\end{array}$ \\
\hline \multirow{2}{*}{$\begin{array}{l}\text { Régimen } \\
\text { familista } \\
\text { doméstico }\end{array}$} & $\begin{array}{l}\text { Doméstico no } \\
\text { facilitado pública- } \\
\text { mente }\end{array}$ & Baleares y Valencia & $\begin{array}{l}\text { No existe una protección } \\
\text { social adecuada y destaca } \\
\text { la evolución del sector } \\
\text { doméstico de cuidados }\end{array}$ \\
\hline & $\begin{array}{l}\text { Doméstico Subven- } \\
\text { cionado }\end{array}$ & Navarra y Murcia & $\begin{array}{l}\text { La contratación de em- } \\
\text { pleadas de hogar es una } \\
\text { opción extendida junto con } \\
\text { las prestaciones económi- } \\
\text { cas }\end{array}$ \\
\hline \multicolumn{2}{|c|}{ Régimen familista opcional } & $\begin{array}{c}\text { La Rioja y País } \\
\text { Vasco }\end{array}$ & $\begin{array}{l}\text { Aparece un equilibrio entre } \\
\text { la provisión de cuidados } \\
\text { estatal, la familiar y la } \\
\text { contratada de manera } \\
\text { privada }\end{array}$ \\
\hline
\end{tabular}




\begin{tabular}{|l|l|l|}
\hline Régimen familista absoluto & $\begin{array}{l}\text { La carga del cuidado recae } \\
\text { en los parientes sin que } \\
\text { exista un apoyo estatal y } \\
\text { sin el desarrollo de un } \\
\text { mercado privado de } \\
\text { asistencia }\end{array}$ \\
\hline
\end{tabular}

Fuente: Elaboración propia

Como vemos, el papel de la política social en la configuración de cada una de estas estrategias varía de un contexto a otro. Cuando los estudios del bienestar se centraron en el análisis de los regímenes de cuidado tendieron a afirmar que la insuficiencia de una red adecuada de servicios sociales era el motivo principal de que la familia fuese la principal dispensadora de asistencia en los países mediterráneos (EspingAndersen, 1998).

Sin embargo, observando la tabla 8 para el caso español, la inexistencia de una protección social adecuada parece tener efectos contradictorios sobre el familismo y la mercantilización de la atención. Por ejemplo, la ausencia de un apoyo estatal en Galicia y Canarias refuerza que las familias continúen como principales dispensadoras sin que aparezca un extenso mercado privado. Pero esta situación no sucede en Baleares y Valencia a pesar de poseer unos niveles similares de atención pública. Estas dos últimas regiones conforman el "modelo doméstico no facilitado públicamente" y en ambas se ha desarrollado un relevante mercado de cuidados en torno al servicio doméstico. Ello induce a pensar que existen otros elementos aparte de la protección social que inciden en el familismo o en la externalización, como pueden ser la incorporación laboral de las mujeres y el porcentaje de población extranjera. Así, en Baleares se combina una de las tasas más bajas de paro femenino, con un 6,2\% de mujeres entre 25-59 años desempleadas, y el peso más elevado de población extranjera de todas las autonomías (un 21,7\%). Galicia, por el contrario, conjuga un elevado nivel de desempleo femenino $(6,2 \%)$ con una escasa recepción de inmigración ya que el peso de los foráneos, un 3,8\%, es de los más bajos del país. El modelo migratorio y la participación laboral de las mujeres cuentan para definir las configuraciones del cuidado (Simonazzi, 2009).

La incorporación del servicio doméstico en las investigaciones de los regímenes de cuidado supuso una revisión de los análisis efectuados sobre la naturaleza de las políticas sociales. Las tendencias privatizadoras de la protección pública en la forma de transferencias monetarias se consideró como una de las principales causas de la mercantilización (Williams y Gavanas, 2008; Bettio et al., 2006; Ellingsaeter y Leira, 2006). Pero una vez más estos efectos dependen de más factores. Sin bien esta situación aparece en el modelo "doméstico subvencionado" de Navarra y Murcia donde un elevado nivel de prestaciones económicas transcurre con un elevado porcentaje de empleadas de hogar contratadas como cuidadoras, no sucede lo mismo en el caso del modelo "familista subvencionado", en donde los subsidios directos tienden a favorecer la dedicación de las mujeres al cuidado en el ámbito familiar. El ejemplo más llamativo, como se ha mencionado en páginas precedentes es el de Andalucía, que 
con un $83,7 \%$ de hogares con personas dependientes que solo reciben ayuda familiar para la atención, el más elevado del país, la cobertura de las prestaciones económicas es también muy relevante $(33,6 \%)$. Las puntuaciones femeninas en desempleo y la instalación de población extranjera vuelven a explicar estas puntuaciones. Mientras que las tasas de paro femeninas de Navarra y de Murcia son de un 6,8 y de un 7,9 respectivamente y el peso de la población foránea es del 11,2 y del 16,3\%, el desempleo de las mujeres en Andalucía sobrepasa el 15\% y el asentamiento de inmigrantes es de un $8,1 \%$.

Los estudios sobre las configuraciones del cuidado demuestran que la defamiliarización, es decir la tendencia a que no sea la parentela la proveedora principal de atención, se desarrolla en aquellos territorios en los que los servicios sociales son más extensos (Leitner, 2003). Pero los datos barajados tampoco indican esta propensión en el caso español. Las regiones con una cobertura más amplia del servicio de ayuda a domicilio muestran también elevadas puntuaciones en cuidados familiares. Esta atención profesionalizada en Madrid, Extremadura, Castilla La Mancha, Cataluña, Castilla y León y Asturias requiere de una elevada participación familiar en la atención. Ello puede ser debido a que los servicios sociales en España no ofrecen cuidados intensivos, sino que suponen tan sólo una ayuda testimonial que no evita la intervención de los parientes. También destaca la posición de Cataluña donde el porcentaje de hogares que solo reciben asistencia familiar es sorprendente (un 82,0\%) si tenemos en cuenta que la tasa de desempleo femenino es muy baja (un 6,0\%). En Extremadura también aparece esta orientación familista pero la prevalencia de mujeres en paro es la más elevada de toda la nación (un 16,1\%) por lo que hace pensar que la cultura de cuidados en ambas regiones es diferente.

Los territorios que ofrecen una oferta más equilibrada de protección social y mercantilización son aquellos en los que más se suaviza el papel de la familia en la provisión de asistencia. En La Rioja y el País Vasco, la amplia cobertura de los servicios sociales, la proliferación de transferencias económicas y la más elevada representación de cuidadoras en el servicio doméstico ha determinado que sean las familias de estas regiones las que puedan escoger con más libertad si desean ser ellas quienes cuiden o si prefieren delegar esta asistencia. La escasa tasa de paro femenina impone la tendencia hacia la mercantilización pero, sin duda, lo que más destaca de esta opción es que la existencia de una adecuada protección social no mitiga la externalización en el cuidado doméstico, sino que por el contrario, la refuerza. Los mayores niveles de bienestar y cohesión social son, por tanto, indicadores de la extensión del sector doméstico de cuidados. 
Tabla 7.- Estrategias de cuidado en España a nivel regional y factores explicativos de las mismas

\begin{tabular}{|c|c|c|c|c|c|c|c|c|c|c|c|c|c|c|c|c|c|}
\hline$\sum_{\substack{0 \\
0}}^{\infty}$ & 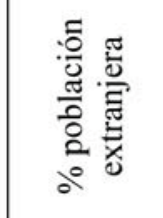 & 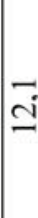 & & $=$ & & 8 & $\vec{\therefore}$ & \pm 2 & ô & $\hat{\varrho}$ & : & & & $\hat{\sigma}=0$ & $\cong$ & & $\begin{array}{l}0 \\
\dot{\Xi}\end{array}$ \\
\hline 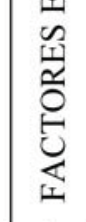 & 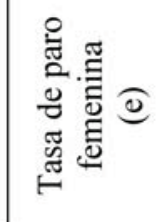 & 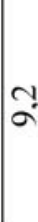 & & 2 & & $=$ & તુ: & $=$ & $=0$ & $\tilde{0}^{n}$ & 6 & $\overrightarrow{0}$ & 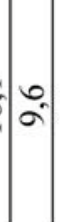 & $\because 2$ & $\infty^{\infty}$ & & in \\
\hline 冚 & 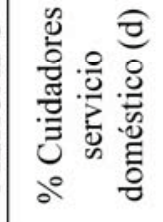 & $\stackrel{n}{ \pm}$ & & ?2: & : & \pm & & 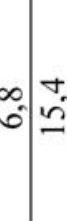 & $\stackrel{\sim}{2}$ & \begin{tabular}{l}
$\mathcal{Y}$ \\
\multirow{\Xi}{*}{}
\end{tabular} & $=$ & 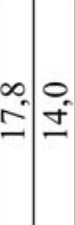 & $\Rightarrow$ & \begin{tabular}{l|l}
0 \\
$\therefore$ & 0 \\
$=$ &
\end{tabular} & $\begin{array}{l}\infty \\
+ \\
\mathbf{d}\end{array}$ & & ลี \\
\hline 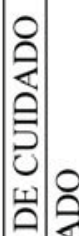 & 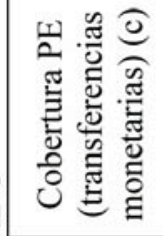 & ¿े. & & ले & & m: & & r. & $\underline{t}$ & तิ & $\overline{\mathrm{A}}$ & 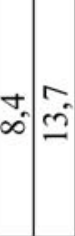 & $\begin{array}{l}n \\
\pm \\
\pm\end{array}$ & \begin{tabular}{l|l}
$\circ$ & - \\
$\dot{f}$ &
\end{tabular} & $\vec{\infty}$ & & $\begin{array}{c}n \\
\infty \\
+ \\
+\end{array}$ \\
\hline 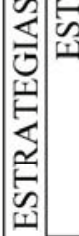 & 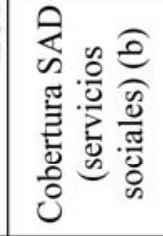 & $\ddot{n}$ & & $=$ & & : & & הิ & $\stackrel{+}{\infty}$ & $\begin{array}{l}n \\
\infty \\
n\end{array}$ & הำ & 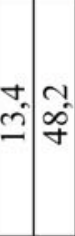 & $-\infty$ & \begin{tabular}{l|l}
$\infty$ \\
if
\end{tabular} & $\left\{\begin{array}{l}2 \\
\infty \\
\infty\end{array}\right.$ & $\begin{array}{c}\text { Na } \\
n \\
m\end{array}$ & $\bar{f}$ \\
\hline$\underset{\Xi}{\leftrightarrows}$ & 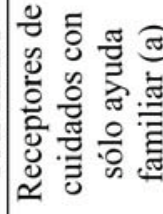 & $\mid \begin{array}{l}\infty \\
\infty \\
\infty\end{array}$ & & के & & & & $\begin{array}{c}n \\
\infty\end{array}$ & $\bar{\infty}$ & $\begin{array}{c}\text { N } \\
\infty \\
\infty\end{array}$ & \begin{tabular}{ll}
0 & 0 \\
\hdashline & 0 \\
$\infty$ & 0
\end{tabular} & \begin{tabular}{l|l}
\multirow{2}{*}{} \\
\multirow{2}{*}{}
\end{tabular} & $\mid \begin{array}{l}0 \\
-1 \\
\infty\end{array}$ & $\begin{array}{ll}n \\
\therefore\end{array}$ & {$\left[\begin{array}{l}\infty \\
6 \\
6\end{array}\right.$} & & 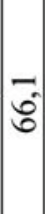 \\
\hline & & & & 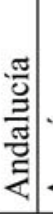 & & 4 & $\frac{\tilde{\nu}}{\tilde{m}}$ & 愛 & 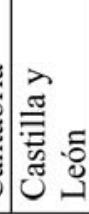 & 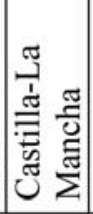 & 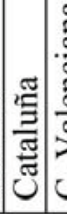 & 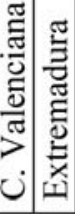 & $\frac{\pi}{0}$ & : & $\mathrm{Z}$ & 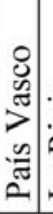 & 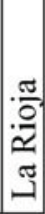 \\
\hline
\end{tabular}


Fuente: Elaboración propia a partir de EDAD, 2008; IMSERSO, 2008; IMSERSO, 2010 y EPA, 2007.

(a) Hogares que sólo reciben ayuda familiar de cuidados dividido entre el número de personas mayores con dependencia (EDAD 2008)

(b) Beneficiarios del servicio de ayuda a domicilio (a 1/1/2008) dividido entre el número de personas mayores con dependencia (IMSERSO, 2009; EDAD, 2008)

(c) Beneficiarios de la PE "Cuidados Familiares" de la LAAD ( a 1/1/2010) dividido entre el número de personas mayores con dependencia (IMSERSO (2010); EDAD, 2008)

(d) Personas mayores que han reciben cuidados de empleados de hogar dividido entre el número de personas mayores con dependencia (EDAD, 2008)

(e) Tasa de paro de la población femenina entre 25 y 59 años. Calculado para el segundo trimestre de 2007 (antes de la crisis económica). (EPA, 2007).

\section{Conclusiones}

La creciente demanda de suministro de asistencia de larga duración y la incorporación laboral de la mujer ha visualizado los límites del sistema familista de provisión y ha supuesto un desafío a la política social del país. Este reto ha culminado con la implantación de la Ley 39/2006 conocida como la Ley de Dependencia que inaugura un nuevo catálogo de servicios sociales y de prestaciones económicas. Sin embargo, con anterioridad a su aprobación ya se estaba produciendo una reestructuración del trabajo familiar de cuidados. Lejos de consistir en un reparto más equilibrado de las tareas asistenciales entre todos los miembros de la familia, esta reorganización estriba en la contratación de una empleada de hogar como cuidadora.

La acelerada llegada de flujos migratorios en esta primera década del siglo XXI altamente feminizados y en situación irregular ha propiciado la extensión del servicio doméstico. Barato y flexible, este modelo de cuidados basado en la incorporación de una migrante a la familia, se ha silenciado en el ámbito legislativo. La mencionada ley no incorpora su figura e incluso potencia mediante transferencias monetarias directas en forma de salario mensual que sea la parentela la principal proveedora. Sin embargo, ante la inexistencia de otras alternativas este proceso de mercantilización parece imparable. Entre los efectos no previstos de esta política social se ha detectado la inversión de los subsidios en la contratación de mujeres inmigrantes en la economía sumergida, por lo que esta normativa ha revertido en el fomento de un mercado de cuidados irregular.

La tendencia hacia la privatización dependerá, además de la naturaleza de la protección social, de otros factores como la participación laboral de las mujeres nativas y el modelo migratorio existente en cada territorio. El análisis a nivel regional de las estrategias de provisión de cuidados y su reparto entre el estado, la familia y el mercado ha corroborado la existencia de variados contextos de familismo, profesionalización y privatización. El resultado es que la contratación más relevante de empleadas de hogar se produce en los lugares de amplia protección social pública y elevada 
participación laboral femenina. En contraposición, el sistema familista más puro prospera en las comunidades más escasas de apoyo estatal y sorprendentemente en los que la cobertura del servicio de ayuda a domicilio es más extensa. Es decir, la red de servicios sociales en España, incluso en sus versiones más desarrolladas, no destituye a las familias de ejercer como cuidadoras si el entorno no ofrece otras fórmulas de provisión.

\section{Bibliografía}

Abellán, A. et al. (2007). A propósito de las condiciones de vida de las personas mayores. Encuesta 2006. Madrid: Ministerio de Trabajo y Asuntos Sociales.

Anttonen, A. y J. Sippilä (1996). European Social Care Services: Is it Possible to Identify Models?. Journal of European Social Policy, 6(2): 87-100.

Benería, L. (2008). The Crisis of Care, International Migration, and Public Policy. Feminist Economics, 14(3): 1-21.

Berjano, E. et al. (2005). El cuidado de personas mayores dependientes realizado por ciudadanos inmigrantes en la Comunidad Valenciana. En IMSERSO (ed.), Cuidado a la dependencia e inmigración (pp 127-231). Madrid: IMSERSO.

Bettio, F. et al. (2006). Change in Care Regimes and Female Migration: The Care Drain in the Mediterranean. Journal of European Social Policy, 16(3): 271-285.

Bettio, F. y J. Plantenga (2004). Comparing Care Regimes in Europe. Feminist Economics, 10(1): 85-113.

Castles, S. y M. Miller (1993). The Age of Migration. New York: The Guilford Press.

CES (2009). Memoria sobre la situación socioeconómica y laboral. Madrid: CES.

Colectivo IOÉ (2001). Mujer, inmigración y trabajo. Madrid: Instituto de Migraciones y Servicios Sociales.

Colectivo IOÉ (2005). El cuidado de personas mayores dependientes realizado por ciudadanos inmigrantes en la Comunidad de Madrid. En IMSERSO (ed.), Cuidado a la dependencia e inmigración (pp 233-370). Madrid: IMSERSO.

Durán, M.A. (2006). Dependientes y cuidadores: el desafío de los próximos años. Revista del Ministerio de Trabajo y Asuntos Sociales, 60. 57-73.

Ehreinreich, B. y A.R. Hochschild (2004). Global Woman. Nannies, Maids and Sex Workers in the New Economy. New York: Henry Holt and Company.

Ellingsaeter, A.L. y A. Leira (2006). Politicizing parenthood in Scandinavia. Gender relations in welfare states. Bristol: Policy Press. 
Esping-Andersen, G. (1990). Three Worlds of Welfare Capitalism. Cambridge Polity Press.

Esping-Andersen, G. (1998), The Social Foundations of Postindustrial Economies, Oxford, University Press.

Finch, J. y D. Groves (1983). Natural Selection: Perspectives on Entitlement to the Invalided Care Allowance. En Finch, J. y D. Groves (eds.), A Labour of Love: women, work and caring (pp 148-166), London: RKP.

Glenn, E. N. (2000). Creating a caring society. Contemporary Sociology, 29(1): 84-94.

Graham, H. (1983). Caring: a Labour of Love. En Finch, J. y D. Groves (eds.), A Labour of Love: Women, Work and Caring (pp 13-30), London: RKP.

Hoschschild, A. (2000). Global Care and Chains and Emotional Surplus Value. En Hutton, W. y A. Giddens (eds.), On the Edge: Living with Global Capitalism (pp 130-146), London: Jonathan Cape.

Instituto de Estadística de Andalucía (2008). Redes familiares y atención a la dependencia en Andalucía. Sevilla: IEA.

IMSERSO (2004a). Apoyo informal a las personas mayores. Estudio 4178 (en línea). http://www.imsersomayores.csic.es/estadisticas/encuestas/index.html

IMSERSO (2004b). Empleados de Hogar. Apoyo a Mayores (en línea). http://wwww.imsersomayores.csic.es/estadisticas/ encuestas

IMSERSO (2005). Cuidado a la dependencia e inmigración. Madrid: IMSERSO.

IMSERSO (2009). Las Personas Mayores en España, 2008. Madrid: Ministerio de Sanidad y Política Social.

IMSERSO (2010). Servicio de Estadísticas de la Subdirección General Adjunta de Valoración, Calidad y Evaluación (en línea).

http://www.imserso.es/dependencia_01/documentacion/estadisticas/datos_estadisti cos_saad/index.htm

INE (2002). Encuesta sobre deficiencias, discapacidades y estado de salud, 1999: resultados detallados. Madrid: INE.

INE (2009). Encuesta de Discapacidades, Autonomía Personal y Situaciones de Dependencia (en línea). http://www.ine.es

King, R. y E. Zontini (2000). The Role of Gender in the South European Immigration Model. Papers, 60: 35-52.

Leitner, S. (2003). Varieties of Familialism: the Caring Function of the Family in Comparative Perspective. European Societies, 5(4): 353-75. 
Lyon, D. y M. Gluksmann (2008). Comparative Configurations of Care Work across Europe. Sociology, 42(1): 101-18.

Marcu, S. (2009). Inmigrantes rumanas en el servicio doméstico y de cuidados de la Comunidad de Madrid. Estudios Geográficos, 267: 463-489.

Martínez, R. (2010). Bienestar y cuidados: el oficio del cariño. Mujeres inmigrantes y mayores nativos, Madrid: CSIC (en prensa).

Martínez, R. (2006). El cuidado de ancianos: un nicho laboral para mujeres inmigrantes y un reto de gestión para las entidades del Tercer Sector".Revista Española del Tercer Sector, 4: 145-173.

Martínez, U. (2000). Evolución y clasificación del trabajo doméstico inmigrante. Ofrim Suplementos, junio: 76-96.

Moreno, L. (2001). La vía media española del modelo de bienestar mediterráneo. Papers, 63-64: 67-82

O'Connor, J. (1993). Gender, Class and Citizenship in the Comparative Analysin of Welfare State Regimes: Theoretical and Methodological Issues. British Journal of Sociology, 44(3):501-18.

Orloff, A.S. (1993). Gender and the Social Rights of the Citizenship: the Comparative Analysis of Gender Relations and Welfare States. American Sociological Review, 4: 303-328.

Parreñas, R. (2001). Servants of Globalization: Woman, Migration and Domestic Work. California: Stanford University Press.

Platzer, E. (2006). From Private Solutions to Public Responsibility and Back Again: The New Domestic Service in Sweden. Gender \& History, 18: 211-221.

Rogero, J. y E. Coppola (2009). El cuidado de las mujeres inmigrantes a las personas mayores: una aproximación desde su uso del tiempo. Comunicación presentada en el I Congreso de la Red Española de Política Social. Oviedo.

Saraceno, C. (1995). Familismo ambivalente y clientelismo categórico en el Estado de Bienestar italiano. En Sarasa, S. y L. Moreno (eds.), El Estado del Bienestar en la Europa del Sur (pp 261-288). Madrid: CSIC.

Sarasa, S. (1993). El servicio de lo social. Madrid: INSERSO.

Sarti, R. (2006). Domestic Service: Past and Present in Southern and Northern Europe. Gender \& History, 18: 222-245.

Simonazzi, A. (2009). Care Regimes and National Employment Models. Cambridge Journal of Economics, 33: 211-32.

Thomas, C. (1993). De-Constructing Concepts of Care. Sociology, 27(4):649-669. 
Tobío, C. et al. (2010). El cuidado de las personas. Un reto para el siglo XXI. Barcelona: Fundación La Caixa.

Ungerson, C. (1999). Personal Assistants and Disabled People: an Examination of a Hybrid Form of Work and Care. Work, Employment \& Society, 13 (4): 583-600.

VV.AA. (2009). Informe final del grupo de expertos para la evaluación del desarrollo y efectiva aplicación de la Ley 39/2006 de 14 de diciembre de promoción de la autonomía personal y atención a las personas en situación de dependencia (en línea). http://www.imsersomayores.csic.es

Vega, C. (2009). Culturas del cuidado en transición. Espacios, sujetos e imaginarios en una sociedad de migración. Barcelona: UOC.

Williams, F. y A. Gavanas (2008). The Intersection of Childcare Regimes and Migration Regimes: a Three-Country Study. En Lutz, H. (ed.), Migration and Domestic Work (pp 13-28). Aldershot: Ashgate. 